\title{
Uma Revisão Sistemática sobre softwares educacionais para o ensino de LIBRAS
}

\author{
Floripes Teixeira Santos ${ }^{1}$, Fábio José Coutinho ${ }^{1}$, Patrick Henrique da S. Brito ${ }^{2}$, \\ ${ }^{1}$ Instituto de Computação - Universidade Federal de Alagoas (UFAL) \\ CEP: 57072-900 - Maceió - AL - Brasil \\ ${ }^{2}$ Universidade Federal de Alagoas (UFAL) \\ CEP: 57309-005 - Campus Arapiraca - Arapiraca - AL - Brasil \\ \{flora, fabio, patrick\}@ic.ufal.br
}

\begin{abstract}
Immersed in a hearing world, the acquisition of sign language for the deaf is usually late, which seriously undermines the social inclusion and educational development of these individuals. In this context, the use of technology has been an important resource to facilitate the acquisition of knowledge and communication of deaf people. In order to meet the educational software available to support teaching and learning LIBRAS a Systematic Literature Review (RSL) was performed cataloged these software and identified pedagogical approaches adopted, assessment instruments and monitoring of learning and technology and guidelines employed in their development.
\end{abstract}

Resumo. Imersos em uma comunidade ouvinte, a aquisição da língua de sinais pelo surdo geralmente é tardia, o que compromete seriamente a inclusão social e desenvolvimento educacional desses indivíduos. Neste contexto, o uso da tecnologia tem se mostrado um importante recurso para facilitar a aquisição de conhecimento e a comunicação de pessoas surdas. A fim de conhecer os softwares educacionais disponiveis para auxiliar o ensinoaprendizado da LIBRAS, foi realizada uma Revisão Sistemática de Literatura (RSL) catalogou esses softwares e identificou as abordagens pedagógicas adotadas, os instrumentos de avaliação e acompanhamento do aprendizado e as tecnologias e diretrizes empregadas no desenvolvimento dos mesmos.

\section{Introdução}

A educação de surdos é um tema que tem gerado diversas discussões no decorrer da história por suas dificuldades e limitações. Inicialmente considerados não educáveis, os surdos foram privados do acesso à educação ou submetidos a métodos educacionais pautados, basicamente, na aquisição da oralidade e que não apresentaram resultados satisfatórios. Uma realidade que comprometeu seriamente o processo educacional das pessoas surdas que foi orientado por uma cultura de segregação social e intelectual.

Buscando reverter essa situação de exclusão, os surdos têm lutado para garantir seus direitos linguísticos e o reconhecimento de sua cidadania. Uma luta que vem apresentando conquistas importantes, dentre as quais: os estudos sobre as línguas de sinais, que provaram sua validade linguística e o papel fundamental que exerce no desenvolvimento intelectual dos surdos [Chomsky 1998]; a concepção de propostas 
V Congresso Brasileiro de Informática na Educação (CBIE 2016)

Anais do XXVII Simpósio Brasileiro de Informática na Educação (SBIE 2016)

pedagógicas que buscam o respeito a diferença e valorização da língua de sinais, e a criação de leis que garantem à pessoa surda o acesso à educação e a sua língua materna, no contexto brasileiro a LIBRAS.

Um dos reflexos dessas conquistas é o acréscimo de 47,6\% no número de alunos com surdez (surdos e pessoas com grande dificuldade de ouvir) matriculados na educação básica entre os anos de 2006 e 2012. Na educação superior, as matrículas passaram de 2.428 alunos, em 2006, para 5.660, em 2011, apresentando um aumento de $133 \%$ [MEC/SECADI 2014]. Apesar desse crescimento, os números também revelam um dado preocupante, apenas $15,62 \%$ das pessoas surdas em idade escolar estão matriculadas. Dentre os fatores que contribuem para a exclusão escolar dos Surdos podem ser citados: o pouco preparo das instituições de ensino e de professores para receber esses alunos; a carência de material didático adequado e a inserção de surdos em salas de aula regulares sem que os mesmos tenham o conhecimento prévio da LIBRAS.

Diante do contexto, o uso da tecnologia tem se apresentado como alternativa interessante para auxiliar na comunicação e na aquisição das competências linguísticas de pessoas surdas. Neste sentido, verifica-se que há uma variedade de recursos disponíveis para este fim, tais como dicionários, jogos, e-books. $\mathrm{O}$ uso de aplicativos através de smartphones, por exemplo, também tem se configurado como instrumento relevante para diminuir a segregação e facilitar a comunicação das pessoas surdas.

Com o objetivo de conhecer os softwares educacionais para apoiar o processo de ensino-aprendizagem da LIBRAS, foi realizada uma Revisão Sistemática de Literatura (RSL) que catalogou esses softwares e identificou as abordagens pedagógicas adotadas, os instrumentos de avaliação e acompanhamento do aprendizado e as tecnologias e diretrizes empregadas no desenvolvimento dos mesmos.

Este artigo encontra-se organizado da seguinte maneira. A Seção 2 apresenta a fundamentação teórica relacionada a temática; $\mathrm{Na}$ Seção 3 é detalha a condução desta RSL; A Seção 4 discute as questões de pesquisa e as considerações finais são apresentadas na Seção 5.

\section{Fundamentação}

Esta seção apresenta uma visão geral acerca dos principais temas relacionados a área de pesquisa desta RSL, educação de surdos.

\subsection{Língua de Sinais}

De acordo com Goldfeld (1997), linguagem é "tudo que envolve significação, que tem valor semiótico, não se restringindo apenas a uma forma de comunicação, e é nela que o pensamento do indivíduo é constituído". Constata-se que através da linguagem o ser humano é capaz de formular o pensamento, construir sua subjetividade, estabelecer relações socioafetivas e apropriar-se da cultura a qual pertence.

Neste sentido, surdos e ouvintes são linguisticamente diferentes. Para os ouvintes, a linguagem se estabelece através do canal oral-auditivo (fala), enquanto que os surdos a obtém por meio do canal viso-gestual (sinais), denominado língua de sinais. A língua de sinais é um sistema linguístico legítimo, com modalidade de percepção e possibilidades de expressão em qualquer nível de abstração. Possui gramática própria, estruturada nos diversos níveis linguísticos: fonológico, morfológico, sintático e semântico [Karnopp and Quadros 2001]. Outro aspecto que deve ser observado sobre a 
V Congresso Brasileiro de Informática na Educação (CBIE 2016)

Anais do XXVII Simpósio Brasileiro de Informática na Educação (SBIE 2016)

língua de sinais é que ela não é ágrafa, pode ser registrada graficamente através do SignWriting, sistema de escrita da língua de sinais.

Por ser tão completa, a língua de sinais se estabelece como veículo adequado para as pessoas surdas obterem suas competências linguísticas. Deve ser adquirida nos primeiros anos de vida para propiciar aos surdos um desenvolvimento pleno como sujeito. Todavia, o contato dos Surdos com sua língua materna geralmente é tardio, não acontece no período apropriado, tal como ocorre com os ouvintes, dado que $96 \%$ dos Surdos são filhos de pais ouvintes que, em geral, não conhecem a língua de sinais.

\subsection{Abordagens pedagógicas na educação de surdos}

Considerar a surdez uma deficiência e não uma diferença linguística entre surdos e ouvintes, fundamentou a ideia de que os surdos eram incapazes ou ineducáveis, por um longo tempo. Assim, até a Idade Média, os surdos foram privados de qualquer possibilidade de desenvolvimento intelectual e moral.

Apenas partir do século XVI foi que se admitiu que o surdo poderia ser educado. E com o propósito do surdo desenvolver o pensamento, adquirir conhecimentos e se comunicar, configuram-se duas orientações divergentes na educação dos surdos: a oralista, que utilizava a língua da comunidade ouvinte na modalidade oral como única possibilidade linguística, e a gestualista, que utilizava gestos e alfabeto manual para alfabetizar o surdo, uma proposta educacional mais apropriada para os surdos [Cardoso and Nantes 2010; Lacerda 1998]. Contudo, a abordagem oralista foi predominante até a década de 60 , período que os insucessos com o método começaram a ser evidenciados.

O descontentamento com o oralismo impulsionou o surgimento de uma nova abordagem para o atendimento e a educação de pessoas surdas, a comunicação total. Nesta proposta, utilizava-se qualquer recurso linguístico comunicativo que permitisse ao surdo estabelecer a comunicação, seja por meio da língua oral, seja pela língua de sinais ou a mescla delas [Carvalho 2010]. Contudo, esse método de ensino também não apresentou bons resultados e fez despontar no cenário educacional a abordagem pedagógica da educação bilíngue.

Esta proposta de ensino estabelece que a educação dos surdos deve se basear em duas línguas com funções diferentes: a língua de sinais como língua materna (L1), para desenvolver o pensamento, e a língua da comunidade ouvinte local como segunda língua (L2) e meio de inclusão na sociedade ouvinte. A proposta da educação bilíngue advoga ainda que cada uma das línguas (L1 e L2) apresentadas ao surdo mantenha suas características próprias e não se "misture" uma com a outra. No contexto brasileiro, a LIBRAS é a L1 e a Língua Portuguesa escrita é a L2 [Carvalho 2010; Lacerda 1998].

Atualmente, tem emergido uma nova forma de conceber a educação de surdos: a pedagogia visual ou pedagogia surda, que propõe práticas pedagógicas que considerem todos os aspectos culturais do surdo, requer o ensino por imagens, filmagens, dramatizações, de forma que o conhecimento lhe seja acessível. [MEC/SECADI 2014].

Neste sentido, a tecnologia tem se apresentado como recurso importante para agregar qualificação às práticas pedagógicas utilizadas no processo educacional dos surdos. Considerando o contexto, tem sido comum o desenvolvimento de softwares educacionais para auxiliar no aprendizado dos surdos. 
V Congresso Brasileiro de Informática na Educação (CBIE 2016)

Anais do XXVII Simpósio Brasileiro de Informática na Educação (SBIE 2016)

\section{Revisão Sistemática de Literatura}

Com o objetivo de recuperar e avaliar os estudos científicos que desenvolveram softwares educacionais para apoiar o processo de ensino-aprendizado de Surdos, foi realizada uma Revisão Sistemática de Literatura (RSL), que identificou as principais lacunas e oportunidades de pesquisa nesta área. A RSL conduzida neste trabalho adotou a metodologia definida por Kitchenham and Charters (2007) e está dividida em três fases: (i) planejamento, (ii) realização e (iii) relatório.

\subsection{Planejamento da Revisão Sitemática de Literatura}

Para a realização desta RSL foram definidas uma questão de pesquisa principal, apresentada no quadro subsequente, e cinco questões de pesquisa específicas para nortear a seleção dos estudos primários analisados na revisão.

\section{“Como os softwares educacionais têm contribuído para o processo} de ensino-aprendizagem da LIBRAS para Surdos?"

A seguir, são apresentadas as questões de pesquisa específicas.

[QP1]:Quais as características dos softwares educacionais disponibilizados para apoiar o ensino da LIBRAS?

[QP2]:Quais abordagens pedagógicas adotadas no desenvolvimento dos softwares?

[QP3]:Os softwares educacionais identificados apresentam algum instrumento para avaliação e acompanhamento do aprendizado? Quais?

[QP4]:Os softwares encontrados foram concebidos seguindo alguma diretriz ou critério para desenvolvimento de software educacional?

[QP5]:Quais os tipos de tecnologias de interface (realidade virtual, realidade aumentada, 3D/2D) foram identificadas nos softwares educacionais?

\subsection{Realização da Revisão Sistemática de Literatura}

As seções subsequentes descrevem as principais etapas envolvidas na condução da revisão sistemática.

\subsubsection{Identificação das Palavras-chave}

As palavras-chave desta RSL foram definidas a partir da questão principal da pesquisa e são apresentadas em destaque a seguir: Como os softwares educacionais têm contribuido para o processo de ensino-aprendizagem da LIBRAS para Surdos?

\subsubsection{Definição da String}

A string de busca da RSL foi gerada a partir da combinação dos termos das palavraschave e seus sinônimos usando os operadores lógicos OR e AND.

String: ((educ* OR ensi* OR apren* OR alfabe* OR letramento) OR (ferrament $*$ OR sistem* OR aplica* OR soft* OR ambient* OR jog*)) AND (libras OR "lingua de sinais" OR "língua brasileira de sinais" OR sinais OR gestual OR "linguagem visual" OR audi* OR surd*)

\subsubsection{Período de Publicação}

Com o objetivo de observar a evolução das pesquisas desenvolvidas na área no decorrer do tempo, esta RSL não restringiu sua busca a um intervalo específico. 
V Congresso Brasileiro de Informática na Educação (CBIE 2016)

Anais do XXVII Simpósio Brasileiro de Informática na Educação (SBIE 2016)

\subsubsection{Tipo de Publicação e Bases de Dados}

Os estudos analisados foram artigos submetidos a revistas e anais de conferências nacionais relacionadas ao tema desta RSL. As bases de busca utilizadas foram: Simpósio Brasileiro de Informática na Educação - SBIE, Workshop de Informática na Escola - WIE, Workshops do Congresso Brasileiro de Informática na Educação WCBIE, Jornada de Atualização de Informática na Educação - JAIE; Workshop de Desafios da Computação Aplicada à Educação - WDCAE, Revista Brasileira de Informática na Educação - RBIE, Revista Novas Tecnologias na Educação-Renote.

\subsubsection{Seleção dos estudos primários}

Para seleção dos estudos primários da RSL, foram definidos os critérios de inclusão e exclusão a seguir.

\section{Critérios de Inclusão (CI):}

[CI1]: Estudos que abordam o desenvolvimento de softwares educacionais para o ensino-aprendizado de LIBRAS.

\section{Critérios de Exclusão (CE):}

[CE1]: Estudos em outros idiomas, que não sejam o português ou o inglês.

[CE2]: Revisões e mapeamentos sistemáticos da literatura.

[CE3]: Estudos que apresentem proposta de solução, artigo filosófico, artigo sobre opinião, artigo de experiência, estudo de caso ou análises comparativas.

[CE4]: Estudos que não respondam nenhuma das questões da RSL;

[CE5]: Estudos duplicados ou redundantes (para estudos de mesma autoria ou relacionados a mesma solução, apenas o mais recente e/ou o mais completo será incluído, a menos que tenham informação complementar).

A Tabela 1 descreve as etapas de seleção dos estudos primários da RSL.

Tabela 1. Etapas do Processo de Seleção dos Estudos Primários

\begin{tabular}{|c|l|}
\hline Etapa 1 & $\begin{array}{l}\text { Após as buscas nas bases de dados para identificar os potenciais estudos primários da RSL, foram excluídos } \\
\text { aqueles não relevantes para as questões investigadas, a partir da leitura dos títulos e das palavras-chave dos } \\
\text { estudos recuperados. Os estudos excluídos nesta etapa não foram mantidos em nenhuma lista. Na dúvida } \\
\text { quanto à inclusão ou exclusão de algum estudo nesta etapa o mesmo foi mantido. }\end{array}$ \\
\hline Etapa 2 & $\begin{array}{l}\text { Leitura do resumo, introdução e conclusão dos estudos selecionados na Etapa 1, sendo então realizada uma } \\
\text { segunda filtragem desses estudos. }\end{array}$ \\
\hline Etapa 3 & $\begin{array}{l}\text { Nesta etapa os estudos foram lidos na íntegra para realizar a filtragem dos estudos que foram analisados na } \\
\text { RSL. }\end{array}$ \\
\hline Etapa 4 & Finalmente, foi realizada a extração dos dados e a avaliação da qualidade dos trabalhos. \\
\hline
\end{tabular}

\subsubsection{Estudos retornados}

A Tabela 2 apresenta uma visão detalhada dos estudos retornados em cada uma das bases nas etapas do processo de seleção.

Tabela 2. Etapas do Processo de Seleção dos Estudos Primários

\begin{tabular}{|l|c|c|c|c|c|}
\hline \multicolumn{1}{|c|}{ Fontes } & Recuperados & Etapa 1 & Etapa 2 & Etapa 3 & Identificação dos estudos \\
\hline RBIE & 08 & 02 & 01 & 01 & (E01) \\
\hline SBIE & 44 & 29 & 20 & 14 & $\begin{array}{c}\text { (E03, E04, E05, E08, E12, E13, E18, E18, E19, } \\
\text { E21, E23, E24, E25, E30, }\end{array}$ \\
\hline WIE & 19 & 12 & 04 & 03 & (E33, E41, E42) \\
\hline WCBIE & 13 & 07 & 04 & 03 & ----- \\
\hline JAIE & 00 & 00 & 00 & 00 & ---- \\
\hline WDCAE & 00 & 00 & 00 & 00 & (E44, E47, E50) \\
\hline Renote & 52 & 15 & 07 & 06 & (E51, E54, E57, E60, E61, E62) \\
\hline \multicolumn{1}{c|}{ TOTAL } & $\mathbf{1 3 6}$ & $\mathbf{6 5}$ & $\mathbf{3 6}$ & $\mathbf{2 7}$ & $\mathbf{2 7}$ \\
\hline
\end{tabular}


V Congresso Brasileiro de Informática na Educação (CBIE 2016)

Anais do XXVII Simpósio Brasileiro de Informática na Educação (SBIE 2016)

O protocolo completo de condução da RSL encontra-se disponível no seguinte endereço: https://sites.google.com/a/ic.ufal.br/rsl-sbie2016/. Neste protocolo, estão os formulários que registraram as etapas 2 e 3 do processo de seleção dos estudos primários; os critérios adotados para avaliar a qualidade desses estudos; bem como as referências dos estudos retornados na Etapa 1.

\section{Discussão das Questões de Pesquisa}

Com o objetivo de verificar a evolução histórica das pesquisas relacionadas ao desenvolvimento de softwares para apoiar a educação de surdos, foi gerado um gráfico que ilustra a distribuição dos estudos analisados nesta RSL agrupados por ano de publicação (Gráfico 1). Com o resultado obtido, contatou-se que apesar da busca não ter limitado um período de tempo, o primeiro estudo publicado nas fontes adotadas, foi em 2003 (E16), revelando que os estudos nesta área são relativamente novos. Também foi verificado que o número de publicações acerca do tema tem oscilado entre uma e três por ano, sendo que, nos anos de 2008 e 2010 nenhum estudo foi publicado. Entretanto, nos últimos dois anos, 2014 (E03, E05, E44, E61, E62) e 2015 (E01, E30, E50, E54), ocorreu um crescimento no número de publicações relacionadas à educação de surdos, evidenciando uma tendência da comunidade científica em desenvolver pesquisas na área

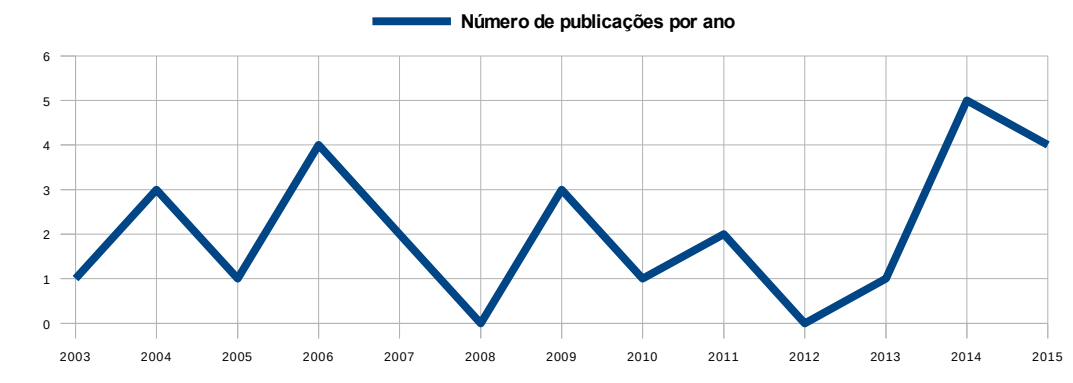

Gráfico 1. Estudos relacionados ao desenvolvimento de softwares para educação de surdos agrupados por ano de publicação

[QP1]: Quais as características dos softwares educacionais disponibilizados para apoiar o ensino de LIBRAS?

Entre os 27 estudos incluídos nesta RSL, foram identificados 28 softwares que apoiam o processo de ensino-aprendizagem dos Surdos. Para caracterizar os softwares encontrados, aspectos pedagógicos e tecnológicos foram catalogados na Tabela 3.

Tabela 3. Características dos softwares educacionais encontrados

\begin{tabular}{|c|c|c|c|c|c|c|c|c|}
\hline Estudo & Categoria & Objetivo & $\begin{array}{c}\text { Tecnologia } \\
\text { Interface }\end{array}$ & Dispositivo & $\begin{array}{l}\text { Público- } \\
\text { Alvo }\end{array}$ & $\begin{array}{l}\text { Faixa } \\
\text { Etária }\end{array}$ & $\begin{array}{l}\text { Abordagem } \\
\text { Pedagógica }\end{array}$ & Ano \\
\hline E01: AssistLibras & $\begin{array}{l}\text { Ferramenta de autoria } \\
\text { animação } 3 \mathrm{D}\end{array}$ & Comunicação & $\begin{array}{c}\text { Animação 3D } \\
\text { (Humano } \\
\text { virtual) } \\
\end{array}$ & Desktop & $\begin{array}{l}\text { Especialista } \\
\text { em LIBRAS }\end{array}$ & $\begin{array}{c}\text { Não } \\
\text { especificada }\end{array}$ & Não especificada & 2015 \\
\hline E03: Deafword & $\begin{array}{l}\text { Ferramenta de autoria } \\
\text { multimídia }\end{array}$ & $\begin{array}{l}\text { Ensino de } \\
\text { Português }\end{array}$ & GUI & Desktop & Surdos & $\begin{array}{c}\text { Não } \\
\text { especificada }\end{array}$ & Não especificada & 2014 \\
\hline $\begin{array}{l}\text { E04: Sign } \\
\text { WebForum }\end{array}$ & $\begin{array}{c}\text { Editor de texto } \\
\text { (fórum de discussão) em } \\
\text { SignWriting e português }\end{array}$ & $\begin{array}{c}\text { Comunicação } \\
\text { na web }\end{array}$ & GUI & Desktop & Surdos & $\begin{array}{c}\text { Não } \\
\text { especificada }\end{array}$ & Não especificada & 2004 \\
\hline E05: JMLP com RA & Jogo & $\begin{array}{l}\text { Ensino de } \\
\text { LIBRAS e } \\
\text { Português }\end{array}$ & $\begin{array}{l}\text { Realidade } \\
\text { Aumentada }\end{array}$ & Desktop & Surdos & Séries iniciais & Educação bilíngue & 2014 \\
\hline E08: SIGNHQ & $\begin{array}{c}\text { Ferramenta de autoria de } \\
\text { História em Quadrinhos }\end{array}$ & $\begin{array}{l}\text { Ensino de } \\
\text { LIBRAS e } \\
\text { Português }\end{array}$ & Animação 3D & Desktop & $\begin{array}{l}\text { Surdos e } \\
\text { ouvintes }\end{array}$ & $\begin{array}{c}\text { Não } \\
\text { especificada }\end{array}$ & Não especificada & 2004 \\
\hline E12: Human Libras & $\begin{array}{l}\text { Animação em 3D } \\
\text { gestos da LIBRAS }\end{array}$ & $\begin{array}{l}\text { Ensino de } \\
\text { LIBRAS }\end{array}$ & $\begin{array}{l}\text { Animação 3D } \\
\text { (Humanoide) }\end{array}$ & Desktop & $\begin{array}{l}\text { Surdos e } \\
\text { ouvintes }\end{array}$ & $\begin{array}{c}\text { Não } \\
\text { especificada }\end{array}$ & Não especificada & 2006 \\
\hline E13: SAESP & $\begin{array}{l}\text { Ambiente de } \\
\text { aprendizagem }\end{array}$ & $\begin{array}{l}\text { Ensino de } \\
\text { Português }\end{array}$ & GUI & $\begin{array}{l}\text { Plataforma } \\
\text { Móvel }\end{array}$ & Surdos & $\begin{array}{c}\text { Fase de } \\
\text { alfabetização }\end{array}$ & Não especificada & 2010 \\
\hline
\end{tabular}


V Congresso Brasileiro de Informática na Educação (CBIE 2016)

Anais do XXVII Simpósio Brasileiro de Informática na Educação (SBIE 2016)

\begin{tabular}{|c|c|c|c|c|c|c|c|c|}
\hline $\begin{array}{l}\text { E16: Sign } \\
\text { WebMessage }\end{array}$ & $\begin{array}{c}\text { Editor de texto } \\
\text { (correio eletrônico) em } \\
\text { SignWriting e português }\end{array}$ & $\begin{array}{c}\text { Comunicação } \\
\text { na web }\end{array}$ & GUI & Desktop & Surdos & $\begin{array}{c}\text { Não } \\
\text { especificada }\end{array}$ & Não especificada & 2003 \\
\hline E18: Sensor Libras & $\begin{array}{c}\text { Tradutor } \\
\text { LIBRAS-Português }\end{array}$ & Comunicação & $\begin{array}{l}\text { Reconhecimento } \\
\text { de movimentos }\end{array}$ & $\begin{array}{c}\text { Luva com } \\
\text { sensores sem } \\
\text { fio e Desktop }\end{array}$ & Surdos & $\begin{array}{c}\text { Não } \\
\text { especificada }\end{array}$ & Não especificada & 2009 \\
\hline E19: Agente Clóvis & $\begin{array}{l}\text { Ambiente de } \\
\text { aprendizagem }\end{array}$ & $\begin{array}{l}\text { Ensino de } \\
\text { Português }\end{array}$ & $\begin{array}{l}\text { Animação 2D } \\
\text { (agente virtual) }\end{array}$ & Desktop & Surdos & $\begin{array}{l}\text { Diferentes } \\
\text { fases }\end{array}$ & Não especificada & 2007 \\
\hline E21: AIAL & $\begin{array}{c}\text { Ambiente de } \\
\text { aprendizagem }\end{array}$ & $\begin{array}{l}\text { Ensino de } \\
\text { LIBRAS }\end{array}$ & GUI & Desktop & $\begin{array}{l}\text { Surdos e } \\
\text { ouvintes }\end{array}$ & $\begin{array}{c}\text { Diferentes } \\
\text { faixas etárias }\end{array}$ & \begin{tabular}{|c|} 
Aprendizagem \\
Baseada em \\
Problemas (PBL) \\
\end{tabular} & 2009 \\
\hline E23: ClassLib & $\begin{array}{c}\text { Tradutor } \\
\text { LIBRAS-Português }\end{array}$ & Comunicação & $\begin{array}{l}\text { Classificador de } \\
\text { imagens e GUI }\end{array}$ & Desktop & $\begin{array}{l}\text { Surdos e } \\
\text { ouvintes }\end{array}$ & $\begin{array}{c}\text { Não } \\
\text { especificada }\end{array}$ & Não especificada & 2007 \\
\hline E24: WebEdit & $\begin{array}{c}\text { Editor de texto } \\
\text { colaborativo (online) em } \\
\text { SignWriting e português }\end{array}$ & $\begin{array}{c}\text { Comunicação } \\
\text { na web }\end{array}$ & GUI & Desktop & Surdos & $\begin{array}{c}\text { Não } \\
\text { especificada }\end{array}$ & Não especificada & 2006 \\
\hline E25: Falibras & $\begin{array}{c}\text { Tradutor } \\
\text { Português-LIBRAS }\end{array}$ & Comunicação & Animação 3D & $\begin{array}{l}\text { Desktop } \\
\text { e Celular }\end{array}$ & $\begin{array}{l}\text { Surdos e } \\
\text { ouvintes }\end{array}$ & $\begin{array}{c}\text { Não } \\
\text { especificada }\end{array}$ & Não especificada & 2004 \\
\hline E30: MVLIBRAS & $\begin{array}{l}\text { Ambiente de } \\
\text { aprendizagem }\end{array}$ & $\begin{array}{l}\text { Ensino de } \\
\text { LIBRAS e } \\
\text { Português }\end{array}$ & GUI & Desktop & $\begin{array}{l}\text { Surdos e } \\
\text { ouvintes }\end{array}$ & $\begin{array}{c}\text { Não } \\
\text { especificada }\end{array}$ & $\begin{array}{l}\text { Aprendizagem } \\
\text { colaborativa }\end{array}$ & 2015 \\
\hline $\begin{array}{l}\text { E33: Sistema Tutor } \\
\text { Inteligente }\end{array}$ & $\begin{array}{c}\text { Ambiente de } \\
\text { aprendizagem }\end{array}$ & $\begin{array}{l}\text { Ensino de } \\
\text { LIBRAS e } \\
\text { Português }\end{array}$ & GUI & Desktop & Surdos & $\begin{array}{l}\text { Crianças em } \\
\text { alfabetização }\end{array}$ & Educação bilíngue & 2009 \\
\hline E41: Libriane & Jogos & $\begin{array}{l}\text { Ensino de } \\
\text { LIBRAS }\end{array}$ & $\begin{array}{l}\text { Animação 2D } \\
\text { GUI }\end{array}$ & Desktop & Surdos & $\begin{array}{l}\text { Crianças da } \\
1^{\mathrm{a}} \mathrm{a} 4^{\mathrm{a}} \text { série }\end{array}$ & Não especificada & 2006 \\
\hline E42: Rybená & $\begin{array}{c}\text { Tradutor } \\
\text { Português-LIBRAS }\end{array}$ & Comunicação & $\begin{array}{l}\text { Animação 2D } \\
\text { (agente virtual) }\end{array}$ & Desktop & $\begin{array}{l}\text { Surdos e } \\
\text { ouvintes }\end{array}$ & $\begin{array}{c}\text { Não } \\
\text { especificada }\end{array}$ & Não especificada & 2011 \\
\hline E44: Glossário & Glossário & $\begin{array}{l}\text { Ensino de } \\
\text { Português }\end{array}$ & GUI & $\begin{array}{l}\text { Plataforma } \\
\text { Móvel }\end{array}$ & Surdos & $\begin{array}{c}\text { Não } \\
\text { especificada }\end{array}$ & $\begin{array}{l}\text { Aprendizagem } \\
\text { colaborativa }\end{array}$ & 2014 \\
\hline $\begin{array}{l}\text { E47: Dicionário } \\
\text { temático interativo }\end{array}$ & Dicionário & $\begin{array}{l}\text { Ensino de } \\
\text { LIBRAS }\end{array}$ & $\begin{array}{l}\text { Realidade } \\
\text { Virtual }\end{array}$ & $\begin{array}{c}\text { Multiprojeção, } \\
\text { Wiimotes e } \\
\text { luva P5-Glove }\end{array}$ & $\begin{array}{l}\text { Surdos e } \\
\text { ouvintes }\end{array}$ & $\begin{array}{c}\text { Não } \\
\text { especificada }\end{array}$ & Não especificada & 2013 \\
\hline E50: Teaching Hand & $\begin{array}{c}\text { Ambiente de } \\
\text { aprendizagem }\end{array}$ & $\begin{array}{l}\text { Ensino de } \\
\text { Português }\end{array}$ & GUI & $\begin{array}{r}\text { Desktop } \\
\text { (online) }\end{array}$ & Surdos & $\begin{array}{l}\text { Crianças do } \\
\text { fundamental }\end{array}$ & Não especificada & 2015 \\
\hline E51: Junctus & $\begin{array}{c}\text { Ferramenta de autoria } \\
\text { multimídia }\end{array}$ & $\begin{array}{l}\text { Ensino de } \\
\text { Português }\end{array}$ & GUI & Desktop & Surdos & $\begin{array}{c}\text { Crianças e } \\
\text { adolescentes }\end{array}$ & $\begin{array}{l}\text { Concepção } \\
\text { Interacionista }\end{array}$ & 2006 \\
\hline $\begin{array}{l}\text { E54: Ferramenta } \\
\text { vocabulário }\end{array}$ & $\begin{array}{l}\text { Ambiente de } \\
\text { aprendizagem }\end{array}$ & $\begin{array}{l}\text { Ensino de } \\
\text { Português }\end{array}$ & GUI & Desktop & Surdos & $\begin{array}{l}5^{\circ} \text { e } 6^{\circ} \text { ano } \\
\text { fundamental }\end{array}$ & Educação bilíngue & 2015 \\
\hline $\begin{array}{l}\text { E57: Projeto Arara } \\
\text { de Brinquedo }\end{array}$ & Jogos & $\begin{array}{l}\text { Ensino de } \\
\text { LIBRAS e } \\
\text { Português }\end{array}$ & GUI & Desktop & Surdos & $\begin{array}{l}\text { Crianças de } \\
03 \text { a } 11 \text { anos }\end{array}$ & Educação bilíngue & 2005 \\
\hline $\begin{array}{l}\text { E60: Ferramenta } \\
\text { amadurecimento do } \\
\text { vocabulário }\end{array}$ & $\begin{array}{l}\text { Ambiente de } \\
\text { aprendizagem }\end{array}$ & $\begin{array}{l}\text { Ensino de } \\
\text { Português }\end{array}$ & GUI & Desktop & Surdos & Fundamental & Educação bilíngue & 2011 \\
\hline $\begin{array}{l}\text { E61: MCHQ-Alfa } \\
\text { (Quadrinhos) }\end{array}$ & $\begin{array}{l}\text { Ambiente de } \\
\text { aprendizagem }\end{array}$ & $\begin{array}{l}\text { Ensino de } \\
\text { Português }\end{array}$ & GUI & Desktop & Surdos & $\begin{array}{c}\text { Não } \\
\text { especificada }\end{array}$ & Educação bilíngue & 2014 \\
\hline E62: HadTalk & $\begin{array}{c}\text { Tradutor } \\
\text { Português-LIBRAS }\end{array}$ & Comunicação & Animação 3D & $\begin{array}{l}\text { Plataforma } \\
\text { móvel }\end{array}$ & Surdos & $\begin{array}{c}\text { Não } \\
\text { especificada }\end{array}$ & Não especificada & 2014 \\
\hline E62: ProDeaf & $\begin{array}{c}\text { Tradutor } \\
\text { Português-LIBRAS }\end{array}$ & Comunicação & Animação 3D & $\begin{array}{l}\text { Plataforma } \\
\text { móvel }\end{array}$ & Surdos & $\begin{array}{c}\text { Não } \\
\text { especificada }\end{array}$ & Não especificada & 2014 \\
\hline
\end{tabular}

Ao analisar a tabela 3 , foi constatado que, dos 28 softwares identificados, apenas quatro (14\%) são destinados ao ensino da LIBRAS (E12, E21, E41, E47). Também foi verificado que, apesar de utilizar a LIBRAS no processo de ensino-aprendizagem, 32\% dos softwares são destinados ao ensino de português como segunda língua e $18 \%$ tem o objetivo de ensinar português numa abordagem bilíngue, com o propósito de ampliar as possibilidades do Surdo interagir com o mundo ouvinte.

Quanto aos tipos dos softwares educacionais, foi observado que houve a predominância de ambientes digitais de aprendizagem, que dispõem de conteúdos instrucionais, atividades didático-pedagógicas e/ou jogos educacionais como recurso para motivar o aluno. A maioria desses ambientes apresentaram dois perfis de usuários (professor e aluno), todavia, alguns também disponibilizaram o perfil de administrador. Outro tipo de software identificado foram as ferramentas de autoria, que tem como proposta educacional incentivar a autonomia do aprendiz na construção do seu conhecimento. 
Constatou-se ainda que $36 \%$ dos softwares catalogados não contêm atividades didático-pedagógicas, se caracterizam pelo aspecto comunicacional, ex. tradutores, dicionários e editores de textos na web. Esses softwares têm o objetivo de viabilizar a interação entre surdos e ouvintes, seja de maneira presencial ou na web. Contudo, é inegável o potencial educacional e a contribuição pedagógica que estas ferramentas apresentam e, por essa razão, foram incluídas nesta RSL. Também foram catalogados editores de texto na web e jogos educacionais.

Esta RSL observou ainda que a maioria dos softwares catalogados está disponível para desktop, mesmo aqueles desenvolvidos mais recentemente. Apenas seis softwares (E13, E25, E42, E44, E62, E62) são disponíveis para plataforma móvel.

Outra questão verificada nesta RSL foi que $57 \%$ dos softwares não especificou a faixa etária do público-alvo, dentre os que informaram, nenhum estava destinado a crianças em idade pré-escolar, entre 2 e 6 anos. Como mencionado, a aquisição precoce da língua de sinais é primordial para o desenvolvimento cognitivo dos surdos.

\section{[QP2]:Quais abordagens pedagógicas adotadas no desenvolvimento dos softwares?}

No desenvolvimento de softwares educacionais é primordial definir uma abordagem pedagógica para consolidar o aspecto educativo dos mesmos [Abreu et al. 2012]. No contexto da educação de surdos, este aspecto é ainda mais relevante considerando que, há a necessidade de se considerar a condição linguística dos surdos em qualquer procedimento didático que eles estejam envolvidos.

Contudo, ao investigar as abordagens pedagógicas empregadas nos softwares, foi verificado que apenas dez estudos (36\%) adotaram uma abordagem pedagógica, tal como mostra a Tabela 4. Esse dado aponta uma carência que pode limitar o potencial educacional dos softwares desenvolvidos e afetar os benefícios destinados aos usuários.

Tabela 4. Abordagens pedagógicas dos softwares encontrados

\begin{tabular}{|l|c|c|}
\hline \multicolumn{1}{|c|}{ Abordagem pedagógica } & $\mathbf{N}^{\mathbf{0}}$ de estudos & Identificação dos estudos \\
\hline Educação bilíngue & 06 & E05, E33, E54, E57, E60, E61 \\
\hline Aprendizagem Colaborativa & 02 & E30, E44 \\
\hline Aprendizagem Baseada em Problemas - PBL & 01 & E21 \\
\hline Concepção Interacionista de Piaget & 01 & E51 \\
\hline
\end{tabular}

Também foi observado que, embora alguns softwares (E01, E05, E12, E33, E47) tenham priorizado o uso da língua de sinais e da percepção visual em seu desenvolvimento, nenhum deles apontou a pedagogia visual como modelo pedagógico.

\section{[QP3]: Os softwares educacionais identificados apresentam algum instrumento} para avaliação e acompanhamento do aprendizado?

Avaliar e acompanhar o processo de aprendizagem do aluno permite ao educador analisar o desenvolvimento educacional deste aluno, constatando se o que foi ensinado está sendo absorvido, bem como obter subsídios para direcionar seus esforços para prover melhorias em seu aprendizado.

Neste sentido, apenas 10 softwares (E04, E13, E19, E21, E30, E33, E4, E54, E60, E61) apresentaram mecanismos que possibilitam acompanhar o aluno nas atividades. Entre os instrumentos de avaliação e acompanhamento identificados, o histórico das interações realizadas pelo aluno, principalmente nos ambientes web, e a elaboração de textos colaborativos, foram os recursos mais utilizados nesse processo. Também foi verificado que as atividades didático-pedagógicas se configuraram, não apenas como 
V Congresso Brasileiro de Informática na Educação (CBIE 2016)

Anais do XXVII Simpósio Brasileiro de Informática na Educação (SBIE 2016)

instrumentos de avaliação, mas também, como meio de acompanhamento do aprendizado. Além disso, dois softwares (E21, E33) adotaram recursos dos sistemas tutores inteligentes (STI) como instrumento de avaliação e acompanhamento do aluno.

[QP4]: Os softwares encontrados foram concebidos seguindo alguma diretriz ou critério para desenvolvimento de software educacional?

Estudos como o de Melonio and Gennari (2013) ressaltam a importância de seguir parâmetros para se obter softwares mais adequados ao contexto educacional e com mais qualidade técnica e pedagógica, bem como apontam diretrizes, sob vários aspectos, para a concepção de softwares educacionais.

Neste contexto, esta RSL verificou que apenas nove estudos explicitaram as diretrizes adotadas na concepção dos softwares. Também foi constatado que, apesar dos softwares catalogados apresentarem o mesmo propósito, educação de surdos, as diretrizes adotadas em seu desenvolvimento foram diferentes. Outro aspecto observado foi que apenas um dos softwares adotou parâmetros de acessibilidade. Também foi notado que, no desenvolvimento dos softwares, foi dada maior atenção aos aspectos computacionais que aos aspectos pedagógicos. A tabela 5 apresenta as diretrizes utilizadas nos softwares desta RSL.

Tabela 5. Diretrizes identificadas no desenvolvimento dos softwares

\begin{tabular}{|c|c|}
\hline ID & Diretrizes para Desenvolvimento de Software \\
\hline E01 & Etapas para geração de ator virtual de Schneider e Nedel (2014) \\
\hline E21/E33 & Técnicas da inteligência artificial \\
\hline E42 & Princípios de keyframing por composição em canais independentes como estratégia de animação em agentes virtuais \\
\hline E44 & Técnicas de aprendizagem colaborativa \\
\hline E61 & Diretrizes de acessibilidade do W3C e recomendações de acessibilidade de Abreu (2010) \\
\hline E16 & Design Pattern Composite para modelagem dos sinais \\
\hline E24 & Quatro princípios básicos de design (alinhamento, proximidade, repetição e contraste) \\
\hline E23 & Técnicas computacionais para a análise e processamento de imagens \\
\hline
\end{tabular}

[QP5]: Quais tecnologias de interface (realidade virtual, realidade aumentada, 3D/2D) foram identificadas nos softwares educacionais?

É através da interface que usuário interage com o computador, sendo assim, as tecnologias empregadas para viabilizar esta interação podem facilitar a usabilidade do software pelos usuários. Considerando que a interface é um atributo importante no desenvolvimento de softwares, esta RSL investigou as tecnologias empregadas nos softwares para educação de surdos.

O estudo verificou que $54 \%$ dos softwares utilizaram a tecnologia Interface Gráfica do Usuário - GUI (Graphical User Interface), que utiliza imagens gráficas e widgets em adição ao texto para representar as informações e ações disponíveis ao usuário. A GUI é considerada uma interface amigável por fornecer um conjunto de componentes que facilitam a utilização da aplicação.

Nove softwares (E01, E08, E12, E19, E25, E41, E42, E62, E62), 32\% dos estudos analisados nesta RSL, utilizaram como meio de interação animações em $2 \mathrm{D}$ e $3 \mathrm{D}$, uma solução interessante para softwares que utilizam humanos virtuais como recurso computacional. Também foi constatado que apenas 04 softwares utilizaram tecnologias como realidade aumentada (E05), reconhecimento de movimento (E18), classificador de imagens (E23) e realidade virtual (E47), embora essas tecnologias se apresentem, atualmente, como alternativas capazes de ampliar a capacidade de representação visual dos softwares, um aspecto relevante nos softwares para surdos. 
V Congresso Brasileiro de Informática na Educação (CBIE 2016)

Anais do XXVII Simpósio Brasileiro de Informática na Educação (SBIE 2016)

\section{Considerações Finais e Trabalhos Futuros}

A RSL realizada neste estudo, identificou importantes lacunas relacionadas ao desenvolvimento de softwares para educação de Surdos e algumas possibilidades de pesquisas nesta área. Primeiramente, foi constatado que nos dois últimos anos houve um crescimento no número de publicações nesta temática revelando, assim, que há uma tendência da comunidade científica em desenvolver pesquisas na área em estudo.

Quanto a concepção dos softwares, foi verificado que a maioria deles tem o propósito de ensinar português para o Surdo como segunda língua, não abordam o ensino de LIBRAS como objetivo principal de seu desenvolvimento. Ainda neste contexto, a RSL evidenciou que há uma carência de softwares educacionais destinados a crianças em idade pré-escolar, entre 2 e 6 anos.

Outro aspecto identificado nesta RSL foi que tecnologias como realidade virtual, realidade aumentada, reconhecimento de movimentos e de imagem ainda são pouco utilizadas na produção dos softwares e podem ser exploradas como proposta de solução no desenvolvimento dos softwares. Ainda neste viés, também foi verificado que dispositivos móveis, bem como outros recursos computacionais que favorecem interatividade, foram pouco utilizados nos softwares.

Além das tecnologias, outras questões igualmente importantes a serem consideradas nas pesquisas para concepção de softwares educacionais são as abordagens pedagógicas e as diretrizes de desenvolvimento, a fim de se obter softwares mais adequados ao contexto educacional e com mais qualidade técnica.

\section{Referências Bibliográficas}

Abreu, F., Almeida, A., Barreiros, E., et al. (2012). Métodos, Técnicas e Ferramentas para o Desenvolvimento de Software Educacional: Um Mapeamento Sistemático. Anais do Simpósio Brasileiro de Informática na Educação, v. 23, n. 1.

Cardoso, F. P. and Nantes, M. S. P. (2010). O ensino da língua portuguesa para o aluno surdo no contexto da sala de aula comum. Diálogos Educacionais Revista, v.1, n. 1.

Carvalho, N. S. (2010). Surdez e Bilinguismo: Perspectivas, Possibilidades e Práticas na Educação para Surdos. Universidade do Estado da Bahia.

Chomsky, N. (1998) "Language and Problems of Knowledge", The Managua Lectures. The MIT Press, Cambridge.

Goldfeld, M. (1997) A criança surda: linguagem e cognição numa perspectiva sóciointeracionista. São Paulo: Plexus.

Karnopp, L. and Quadros, R. M. De (2001). Educação infantil para surdos. A criança de 0 a 6 anos e a educação infantil: um retrado multifacetado, p. 214-230.

Kitchenham, B. and Charters, S. (2007). Guidelines for performing Systematic Literature Reviews in Software Engineering. 2.3 ed. Durham.

Lacerda, C. B. F. De (1998). Um pouco da história das diferentes abordagens na educação dos surdos. Cadernos CEDES, v. 19, n. 46, p. 68-80.

MEC/SECADI (2014). Relatório sobre a Política Linguística de Educação Bilíngue Língua Brasileira de Sinais e Língua Portuguesa. http://www.bibliotecadigital.unicamp.br/document/?code=56513, Maio 16.

Melonio, A., \& Gennari, R. (2013). How to design games for deaf children: evidencebased guidelines. In 2nd International Workshop on Evidence-based Technology Enhanced Learning (pp. 83-92). Springer International Publishing. 